\title{
Risks and Risks Mitigations in the Supply Chain of Mangosteen: A Case Study
}

\author{
Retno Astuti \\ Department of Agroindustrial Technology, Faculty of Agricultural Technology \\ University of Brawijaya, Malang, Indonesia \\ E-mail: retno_astuti@ub.ac.id \\ Marimin, Machfud, Yandra Arkeman \\ Department of Agroindustrial Technology, Faculty of Agricultural Technology \\ Bogor Agricultural University (IPB), Bogor, Indonesia \\ E-mail: marimin@ipb.ac.id (Corresponding Author) \\ Roedhy Poerwanto \\ Department of Agronomy and Horticulture, Faculty of Agriculture \\ Bogor Agricultural University (IPB), Bogor, Indonesia \\ Miranda P. M. Meuwissen \\ Department of Business Economics, Wageningen University, The Netherlands
}

\begin{abstract}
Mangosteen (Garcinia mangostana $L$. .) is the highly demanded fruit for export commodity from Indonesia. The biggest mangosteen production center in Indonesia is West Java Province. The development of the mangosteen supply chain in Indonesia, particularly in West Java Province is heavily affected by uncertain potential risks for the chain. This paper identifies potential risks of the supply chain and studies the interrelationships between strategies for mitigating those risks. Fuzzy Analytical Hierarchy Process (AHP) was utilized to identify the main risks then Interpretive Structural Modeling (ISM) was used to illustrate the interrelationship of those risks mitigations. Data were gathered through questionaires guided interviewing the experts of mangosteen business. Results show that the main risks of the chain to reach its goal are business relationships between partners and return on investment uncertainty. Horizontal coordination and trust building between partners should be considered to mitigate those risks as these strategies are found to have a strong driving power to influence others risks mitigation strategies. Improved coordination and trust building may advocate the Indonesian government to facilitate the provision of soft loans to agricultural businesses, which enables the farmers' cooperative to buy mangosteen in cash therewith improving their return on investment.
\end{abstract}

Keywords: Risk identification, risk mitigation, fuzzy AHP, ISM, mangosteen supply chain

\section{INTRODUCTION}

The activities of mangosteen production in West Java Province, Indonesia for the export market have not been efficient yet to compete internationally, as the farmers only have small scale farms which are located in various places and are managed individually, as well as there is a lack of farmers' skills in maintaining their farms and in managing the mangosteen business.

The strategy to win the global competition should include the enhancement of the cooperation between business partners and the all-out effort to meet the customer demands (Marimin et al., 2010). In order to have competitive advantages in facing the market demand and consumers' preference of mangosteen, supply chain management in mangosteen business was initiated in Bogor district in 2007 by a cooperative of farmers, Al-Ihsan, which integrated processes from receiving raw material to selling finished products (Directorate General of Horticulture, 2008). Introduction new system in developing more integrated mangosteen supply chain is heavily affected by uncertainty which can potentially turn out into unexpected disruptions. Identification of several potential risks which could affect supply chain will give decision makers a more comprehensive view of potential problems to occur so that supply chain risk mitigation strategy can be well defined to minimize the expense of increasing the risk of disruptions.

The risks in the supply chain can be mitigated if the members of the chain understand the risks and risk mitigations which have impact on risk management in the supply chain. Risk sources of the chain should be identified according to all the members of the chain. It is also important for the members of the chain to understand that their risk susceptibility is dependent on other constituents of their supply chain. The previous researches only identified risks on farmer level (Szèp et al., 2000; Meuwissen et al., 2001; Ahsan and Roth, 2009). Furthermore, they did not involve an understanding of how various risk mitigation interact with each other. The objective of this study were to identify potential risk of the supply chain of mangosteen supply chain for exported mangosteen in Bogor District, West Java Province and understand the interrelationship of strategies to mitigate those risks. 
The research focused on mangosteen supply chain in West Java Province, Indonesia as the case study. West Java Province was the biggest mangosteen production center in Indonesia of which Bogor, Purwakarta, Subang, and Tasikmalaya Districts produce the most. Mangosteen productions from these districts contribute $90 \%$ to mangosteen production in West Java Province itself and $29 \%$ to national mangosteen production (Directorate General of Horticulture 2009). Mangosteen supply chain in Bogor District was also a pilot area of mangosteen supply chain in West Java. This supply chain model will be applied and adapted to other supply chain of mangosteen in other districts.

The next section will review some literature about risk then will be followed by a section which describe briefly about the supply chain of mangosteen in Bogor District, Indonesia. The methods used in the research as well as questionnaire design and data collection then will be explained in the Methodology section. The Result and Discussion section is the next which will present and discuss the findings of the research. Finally, the last section is conclusions and future outlook of the research.

\section{Literature Review}

\subsection{Supply Chain of Agricultural Commodities}

According to Vorst (2000), the supply chain of agricultural commodities in general are distinguished into 2 main types: (1) Supply chain for fresh agricultural products (such as fresh vegetables, flowers, fruits and other commodities which do not require special processing or chemical transformation process). The main processes are the handling, storing, packing, transportation, and especially trading of these commodities. In general, these SCs may comprise growers, auctions, wholesalers, importers and exporters, retailers and speciality shops and (2) Supply chain for processed agricultural products (such as snacks, desserts, canned food products). In these supply chains, agricultural products are used as raw materials for producing consumer products with higher added value. A processed agricultural product requires a process of chemical transformation or change in shape. In most cases, conservation and conditioning processes extend the shelf life of agricultural products. Supply chain for processed agricultural products involves several players, i.e. farmers, manufacturers, distributors, and retailers (retail).

Each member of supply chain of agricultural commodities is positioned in a network layer and belongs to at least one supply chain: i.e. it usually has multiple (varying) suppliers and customers at the same time and over time. More than one supply chain and more than one business process that can be identified in the agricultural supply chain network. At a time, parallel and sequential processes can occur in the supply chain of agricultural commodities (Vorst 2006). Supply chain is generally defined as a consumer-driven system, but the supply chain of agricultural commodities can be defined as a system of producer-consumer-driven. Supply and demand forecasting have equal importance in the supply chain of agricultural commodities, but the members of the supply chain have limited ability to control it (Bailey et al, 2002). Supply chain of agricultural commodities is also quite distinctive because of the characteristic of agricultural commodities is very sensitive to time. Therefore, inventory management, transportation, and other supply chain components should be designed by considering the characteristic.

Several studies on supply chain of agricultural commodities, especially for horticultural commodities have been done by some researchers. In 2006, Araki et al. analyzed the supply chain of fruit and vegetables systematically by the PCM (Project Cycle Management) approach at the Kramat Jati central wholesale market which was selected as a case. Dimyati and Muharam (2006) studied the development of a mangosteen supply chain to increase income and the bargaining position of the growers. An analysis of the supply chain of fresh fruit and vegetables was also done by Hart et al. (2007) in Germany. In 2008, Marimin studied the supply chain of perishable horticulture products in Indonesia.

\subsection{Risk in Supply Chain}

The definition of the term "risk" strongly depends on the context and field of research involved (Spekman and Davis 2004). According to Hardaker et al. (2004), risk is broadly defined as uncertain consequences and especially unfavorable consequences. An operational definition in the context of supply chain, risk is the damage assessed by its probability of occurrence that is caused by an event within a company, within its supply chain or its environment affecting the business process of at least one company in the supply chain negatively (Kersten et al., 2006). Supply chain risk refers to the uncertainty of the occurrence of an event that could affect one (or more) partner or link within the supply chain and that could influence (generally in a negative sense) the achievement of company's business objectives (Deloitte and Touche 2008; Tang 2006).

Risk is the possibility of adversity or loss, and refers to the uncertainty that matters. International Organization for Standardization (2002) acknowledges that the common sense definition of risk mainly deals with two of its essential components: losses (along with related amounts) and uncertainty of their occurrence. Consequently, risk management in supply chain involves choosing among alternatives to reduce the effects of risks for all member of the chain. Supply chain risk management is defined as a concept of supply chain management which contains all strategies and measures, all knowledge, all institutions, all process, and all technologies which can be used on the technical, personal, and organizational level to reduce supply chain risk (Kersten et al., 2006). The aim of supply chain risk management is to control, monitor and evaluate supply chain risk, optimizing actions in order to prevent disruptions (that is, the occurrence of an event that causes a business interruption) or to quickly recover from them (Deloitte and Touche 2008; Tang 2006).

Understanding risk is a starting point to help producers make good management choices in situations where adversity and loss are possibilities (Harwood et al., 1999) then identifying the risk sources is a critical step in managing the risks inherent in all member of the chain. By identifying the risk sources the risk decision makers become conscious about events or phenomena that cause uncertainty. According to Hardaker et al. (2004), the most important sources of risk to farming can be classified as 
follows: (1) Production which are related to the unpredictable nature of the weather and to the uncertain performance of crops and livestock, (2) Market which refer to uncertainty of prices and markets of farm inputs and outputs, (3) Institutional which is associated with changes in the policy framework (agricultural and other policies) which intervene with production and / or marketing decisions and in the end negatively affect the financial result of a farm, (4) Human or personal which is related to skill and knowledge as well as the welfare of the farm operator and / or its labor force, (5) Financial which refer to the risks related to the way farm is financed.

Some research on supply chain risk has been performed in agricultural sector. Szèp et al. (2000) explored the importance of the different sources of risk related to horticultural production in horticultural farms of Hungary. Possible ways to prevent the occurrence or reduce the possible negative effects of risk and behavior of horticultural producers faced with different kinds of risks were examined. The statistical analysis of survey results showed that high rank of price (input-output), market risks, and counterpart risk were risk sources of horticultural production in horticultural farms of Hungary. Growing several types of plants, contract in selling products, join some integration, and off-farm investment were used as the ways to prevent the occurrence or reduce the possible negative effects of risk. Meuwissen et al. (2001) studied survey data of Dutch livestock farmers relating to farmers' perceptions of risk and risk management using multivariate regression, and analyses whether characteristics of a farm and/or farmer can be identified that relate to these perceptions. The results showed that, in general, price and production risks were perceived as important sources of risk. Insurance schemes were perceived as relevant strategies to manage risks. Exploratory study to provide empirical insight into how the mussel farmers manage risks in their businesses was conducted by Ahsan and Roth (2009). The results of the study indicated that changes in public regulation, human risks and market risks are the high ranked risks in mussel farming. On the other hand, experience sharing among the farmers, good relation with government and solvency are considered most important risk management strategies.

\section{SUPPLY CHAIN OF MANGOSTEEN IN BOGOR DISTRICT}

Mangosteen supply chain in Bogor District, West Java Province was initiated by a cooperative of farmers, AlIhsan, in 2007. Before 2007, the relationship between participants in mangosteen flow was merely transactional i.e. without functional organization relationship which had the same objectives between participants, cooperative performance management, and shared information in a long period. The conventional system of marketing also lowered the bargaining position of farmers (Dimyati and Muharam, 2006).

Cooperative of farmers is an organization that initiates the relationship with other partners and stimulates the entire chain to conduct the business process. The partners of cooperative of farmers in mangosteen supply chain were 75 farmers which were grouped in 7 farmers groups (or 8-13 farmers each group), an exporter, Centre for Tropical Fruit Studies, Horticultural Partnership Support Program (HPSP), and Agricultural Office of Bogor District. Cooperative of farmers sells fresh export quality mangosteen fruits to the exporter and fresh domestic quality mangosteen fruits to local market. The biggest export market for mangosteen fruits is China. Mangosteen supply chain for export market in the case studied is shown in Figure 1.

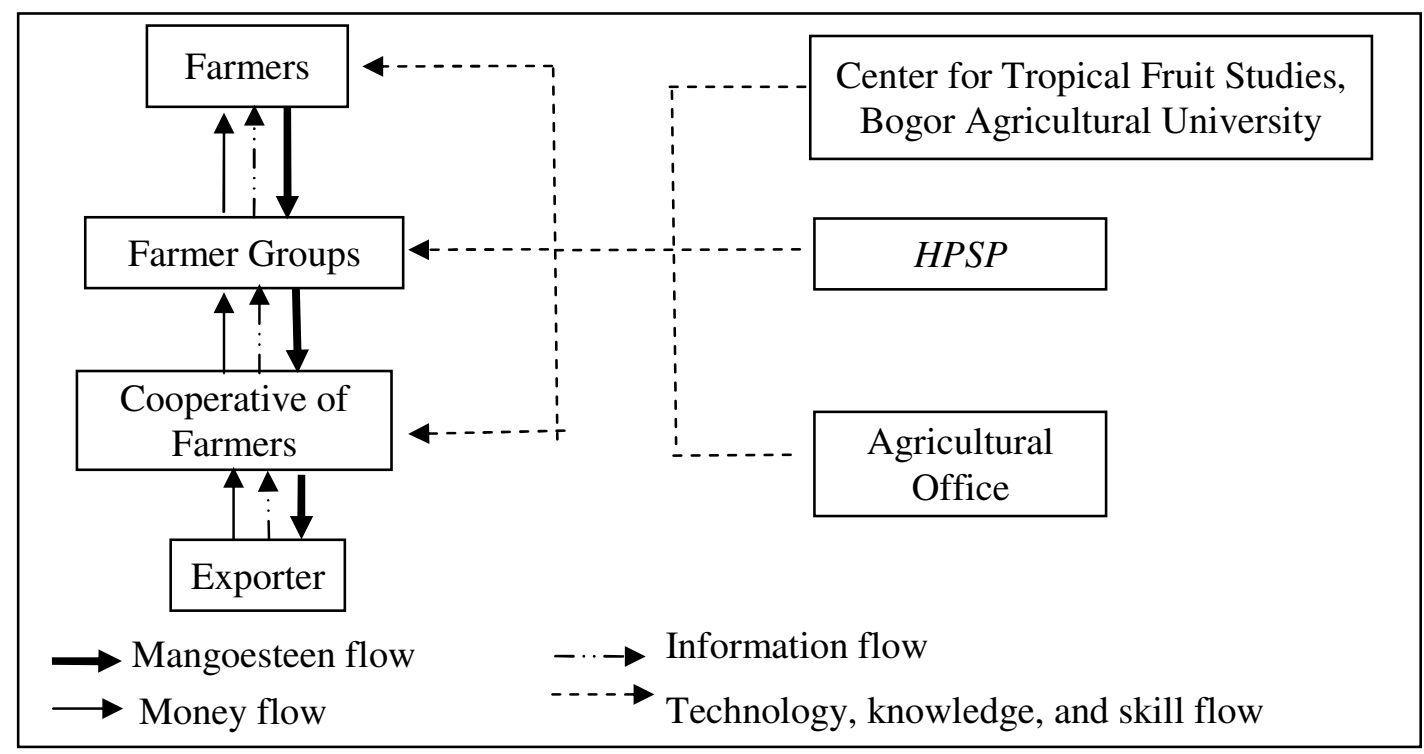

Figure 1. Mangosteen Supply Chain in Bogor District, West Java Province for Export Market

Each member of the chain has its role. Farmers cultivate and harvest fruits of various size and quality from their own mangosteen trees and maintain their mangosteen trees. Farmer groups then collect fruits from farmers, deliver the fruit to cooperative of farmers' warehouse, record all activities of their members in maintaining their orchards, and coordinate farmers in maintaining their farms. 
Farmers and farmer groups' activities are coordinated by cooperative of farmers as initiator of mangosteen supply chain in Bogor District, West Java, Indonesia. The farmers' cooperative also has others roles, such as collecting fruits of various size and quality from the farmers groups, sorting the fruits, connecting and negotiating with the exporters, delivering and selling the fruit to the exporter, selling the domestic quality grade fruits returned by exporter in local market, supplies farm inputs, and connects to the chain supporter institutions to get a transfer of knowledge in maintaining farms and managing the business process.

The only one exporter in this supply chain is PT Agung Mustika Selaras. The exporter buys fruits from cooperative of farmers, sorts and grades them into those of export quality and those of domestic quality, packs the fruits in export packaging, delivers them to the airport, sends them abroad, and pays cooperative farmers in cash.

The supporter institutions of the chain are Center for Tropical Fruit Studies which is one of Center Studies of Bogor Agricultural University, Horticultural Partnership Support Program (HPSP), and Agricultural Office of Bogor District. The university gives training to farmers and monitors activities related to maintain the farms and business process of the supply chain regularly as well as conducting researches and developments activities of mangosteen commodity. Horticultural Partnership Support Program gives grants for the supply chain development, and the government facilitates physical buildings, such as building for activities of farmer cooperative.

\section{METHODOLOGY}

The efficiency and performance of supply chain can be enhanced when strategy to mitigate the risks of the chain takes into account the sources of the risk and relationship of the risks to the goals of the chain (Moeinzadeh and Hajfathaliha 2009). Therefore, potential risks identification as critical steps in managing risks in supply chain of mangosteen were evaluated among alternatives based on the goals of the chain and the sources of the risks. It means that evaluating potential risks of mangosteen supply chain is multi-criteria decision making. Analytical Hierarchy Process is a method for ranking decision alternatives and selecting the best one when the decision maker has multiple criteria (Taylor 2004). The basic advantage of using a hierarchy structure is that the understanding of its highest level is obtained from the interactions among the various lower levels (Siquiera et al., 2008). Due to the vague and imprecise attitudes of human judgment for the potential risks evaluation, fuzzy synthetically evaluation methods were applied to the AHP methods. In this research, fuzzy Analytical Hierarchy Process (fuzzy AHP) method developed by Saaty (1981) and Zadeh (1994) was used to identify potential risks of the supply chain.

Developing more integrated supply chain of mangosteen in Bogor District will increase the complexity of the supply chain. In the complex system, decision making situations involve many interacting causes and effects. Individual or a group can deal more effectively with systems and make better decisions concerning systems when the structure of the system is well defined. ISM (Interpretive Structural Modeling) is a process that helps individuals or groups of people in structuring their collective knowledge and it refers to the systematic application of graph theory in such a way that theoretical, conceptual, and computational leverage is exploited to efficiently construct a directed graph, or network representation, of the complex pattern of a contextual relationship among a set of elements (Anantatmula and Kanungo 2005). In other words, it helps to identify structure within a system of related elements. In this research, risk mitigations interrelationship in supply chain of mangosteen in Bogor District was clarified and analyzed by using ISM.

The supply chain of mangosteen in Bogor District was just built so that it has limitation in data availability to achieve minimal sample size requirement when using statistical methodology as previous researches used. Fuzzy AHP and ISM are subjective methods with experts judgements as the main data used those are not necessary to involve a large sample. A small sample (in this case are representative expert judgements) is useful for research focusing on a specific issue where a large sample is not mandatory (Cheng and Li 2002). Furthermore, fuzzy AHP and ISM allows decision makers to model a complex problem in a structure portraying the relationships of the alternatives considered choosing risks sources and mitigations of the risks in this research. Therefore, fuzzy AHP and ISM were used in this research. Overall approach for this study is shown in Figure 2.

\subsection{Fuzzy Analytical Hierarchy Process (AHP)}

Saaty (1981) proposed AHP as a decision aid to help solve unstructured problems in economics, social and management sciences. In AHP, preferences between alternatives are determined by making pair-wise comparisons in which the decision maker examines two alternatives by considering one criterion and indicates a preference. These comparisons are made using a preference scale, which assigns numerical values to different levels of preference (Taha 2003). The standard preference scale used for AHP is 1-9 scale which lies between "equal importance" to "extreme importance" (Saaty 1989).

The main advantage of AHP is its ability to handle complex and ill-structured problems which cannot be usually handled by rigorous mathematical models. In addition to simplicity, ease of use, flexibility, and intuitive appeal, the ability to mix qualitative and quantitative criteria in the same decision framework has led to AHP's power and popularity as a decision making tool. The ability to monitor the consistency with which a decision maker makes judgment is other advantages of AHP (Muralidharan et al., 2002).

Despite the convenience of AHP in handling multicriteria decision making problems based on decision makers' judgments, fuzziness and vagueness existing in many decision-making problems may contribute to the imprecise judgments of decision makers in conventional AHP approaches (Bouyssou et al., 2000). The uncertainty in the preference judgments gives rise to uncertainty in the ranking of alternatives as well as difficulty in determining consistency of preferences (Leung ve Chao 2000). Fuzzy AHP approach is proposed to makeup the vagueness and existing uncertainty in deciding the weight of alternatives by the decision maker (Özdağoğlu and Özdağoğlu 2007). 


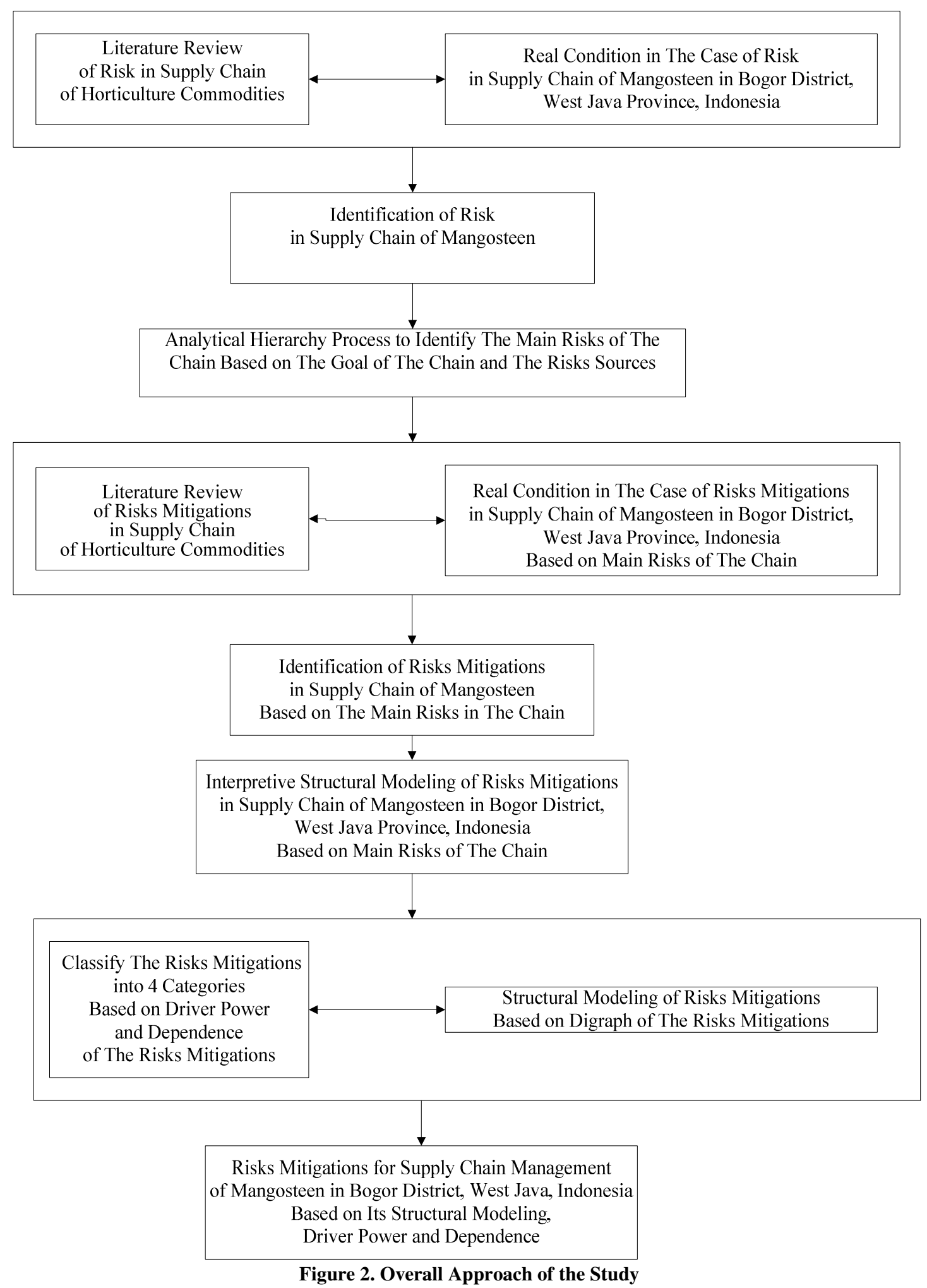

In this study, triangular fuzzy numbers, $\tilde{1}-\tilde{9}$ (the signs above the numbers refer to the fuzzy number), were utilized to improve the conventional nine-point scaling scheme. In order o take the imprecision of human qualitative assessments into consideration, the five triangular fuzzy numbers were defined with the corresponding membership function.

Ayağ and Özdemir (2006) gave four-step-procedure of fuzzy AHP approach as follows:
1. Comparing the score. Triangular fuzzy numbers are used to indicate the relative strength of each pair of elements in the same hierarchy.

2. Constructing the fuzzy comparison matrix: By using triangular fuzzy numbers, via pairwise comparison, the fuzzy judgment matrix $\widetilde{A}\left(a_{i j}\right)$ is constructed as given below: 


$$
\tilde{A}=\left[\begin{array}{ccccc}
1 & \tilde{a}_{12} & \cdots & \cdots & \tilde{a}_{1 n} \\
\tilde{a}_{21} & 1 & \cdots & \cdots & \tilde{a}_{2 n} \\
\vdots & \vdots & \cdots & \cdots & \vdots \\
\vdots & \vdots & \cdots & \cdots & \vdots \\
\tilde{a}_{n 1} & \tilde{a}_{n 2} & \cdots & \cdots & 1
\end{array}\right]
$$

where $\tilde{a}_{i j}^{\alpha}=1$ if $\mathrm{i}=\mathrm{j}$, and $\tilde{a}_{i j}^{\alpha}=\tilde{1}, \tilde{3}, \tilde{5}, \tilde{7}, \tilde{9}$ or $\tilde{1}^{-}$ $1, \tilde{3}^{-1}, \tilde{5}^{-1}, \tilde{7}^{-1}, \tilde{9}^{-1}$ if $\mathrm{i} \neq \mathrm{j}$

3. Solving fuzzy eigen-value: A fuzzy eigen-value, $\tilde{\lambda}$, is a fuzzy number solution to

$$
\tilde{A} \tilde{x}=\tilde{\lambda} \tilde{x}
$$

where is nxn fuzzy matrix containing fuzzy numbers $\tilde{a}_{i j}$ and $\tilde{x}$ is non-zero $\mathrm{nx} 1$ fuzzy vector containing fuzzy number $\tilde{x}_{i}$. In order to perform fuzzy multiplications and additions by using the interval arithmetic and $\alpha$-cut, the equation $\tilde{A} \tilde{x}=\tilde{\lambda} \tilde{x}$ is equivalent to

$$
\begin{aligned}
& {\left[a_{i 1 l}^{\alpha} x_{1 l}^{\alpha}, a_{i 1 u}^{\alpha} x_{1 u}^{\alpha}\right] \oplus \ldots \oplus\left[a_{i n l}^{\alpha} x_{n l}^{\alpha}, a_{i n u}^{\alpha} x_{n u}^{\alpha}\right]=[} \\
& \left.\lambda x_{i l}^{\alpha}, \lambda x_{i u}^{\alpha}\right]
\end{aligned}
$$

where

$$
\begin{aligned}
& \tilde{A}=\left[\tilde{a}_{i j}\right], \tilde{x}^{t}=\left(\tilde{x}_{1}, \ldots, \tilde{x}_{n}\right) \\
& \tilde{a}_{i j}^{\alpha}=\left[a_{i l l}^{\alpha}, a_{i 1 u}^{\alpha}\right], \quad \tilde{x}_{i}^{\alpha}=\left[x_{i l}^{\alpha}, x_{i u}^{\alpha}\right],
\end{aligned}
$$

$\tilde{\lambda}^{\alpha}=\left[\lambda_{i l}^{\alpha}, \lambda_{i u}^{\alpha}\right]$

for $0<\alpha \leq 1$ and all $i, j$, where $i=1,2, \ldots, n, j=1,2$, $\ldots, n$

$\alpha-c u t$ is known to incorporate the experts or decision maker(s) confidence over his/her preference or the judgments. Degree of satisfaction for the judgment matrix $\widetilde{A}$ is estimated by the index of optimism $\mu$. The larger value of index $\mu$ indicates the higher degree of optimism. The index of optimism is a linear convex combination (Lee 1999) defined as

$$
\tilde{a}_{i j}^{\alpha}=\mu a_{i j u}^{\alpha}+(1-\mu) a_{i j l}^{\alpha}, \forall \mu \in[0,1]
$$

While $\alpha$ is fixed, the following matrix can be obtained after setting the index of optimism, $\mu$, in order to estimate the degree of satisfaction.

$$
\tilde{A}=\left[\begin{array}{ccccc}
1 & \tilde{a}_{12}^{\alpha} & \cdots & \cdots & \tilde{a}_{1 n}^{\alpha} \\
\tilde{a}_{21}^{\alpha} & 1 & \cdots & \cdots & \tilde{a}_{2 n}^{\alpha} \\
\vdots & \vdots & \cdots & \cdots & \vdots \\
\vdots & \vdots & \cdots & \cdots & \vdots \\
\tilde{a}_{n 1}^{\alpha} & \tilde{a}_{n 2}^{\alpha} & \cdots & \cdots & 1
\end{array}\right]
$$

The eigenvector is calculated by fixing the $\mu$ value and identifying the maximal eigenvalue. $\alpha-$ cut: It will yield an interval set of values from a fuzzy number. For example, $\alpha=0.5$ will yield a set $\alpha_{0.5}=(2,3,4)$. The operation is presented by using Figure 3 .

Normalization of both the matrix of paired comparisons and calculation of priority weights (approximate. attribute weights), and the matrices and priority weights for alternatives are also done before calculating $\lambda_{\max }$. In order to control the result of the method, the consistency ratio for each of the matrices and overall inconsistency for the hierarchy are calculated.

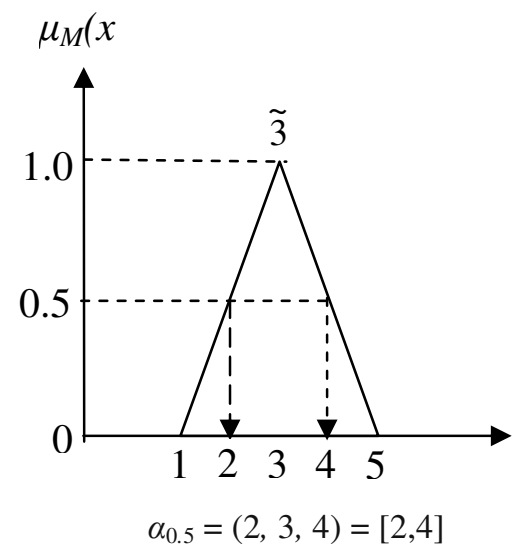

Figure 3. $\alpha$-cut Operation on Triangular Fuzzy Number

The deviations from consistency are expressed by the following equation $C I$, and the measure of inconsistency is called the $C I$,

$$
C I=\frac{\lambda_{\max }-n}{n-1}
$$

The consistency ratio $(C R)$ is used to estimate directly the consistency of pairwise comparisons. The $C R$ is computed by dividing the $C I$ by a value obtained from a table of Random Consistency Index $(R I)$ :

$$
C R=\frac{C I}{R I}
$$

If the $C R$ less than 0.10 , the comparisons are acceptable, otherwise not. $R I$ is the average index for randomly generated weights (Saaty 1981).

\subsection{Interpretive Structural Modelling (ISM)}

ISM is a method which can be applied to a system, such as a network or a society, to better understand both direct and indirect relationships among the system's components (Gorvett and Liu 2006). Its basic idea is to use experts' practical experience and knowledge to decompose a complicated system into several sub systems (elements) and construct a multilevel structural model. ISM is often used to provide fundamental understanding of complex situations, as well as to put together a course of action for solving a problem (Gorvett and Liu 2006).

In order to clarify risk mitigations interrelationship in supply chain of mangosteen in Bogor, experts who represent members of chain or those who have expertise in mangosteen business, were asked to list the risk mitigations considered affecting the chain. A contextual relationship then was established among risk mitigations with respect to which pairs of risk mitigations would be examined. The next step was developing a structural self-interaction matrix (SSIM) which indicates pairwise relationships among risk mitigations of the chain. Based on the adjacent matrix, a reachability matrix (a binary matrix which elements are 0 or 1) that reflects the directed relationship between the risk mitigations, was created then the matrix was checked for transitivity (Faisal 2010). According Faisal (2010), the rules for the substitution of 1's and 0's were as follows: 
- If the $(i, j)$ entry in the SSIM is $V$, then the $(i, j)$ entry in the reachability matrix becomes 1 and the $(j, i)$ entry becomes 0 .

- If the $(i, j)$ entry in the SSIM is $A$, then the $(i, j)$ entry in the reachability matrix becomes 0 and the $(j, i)$ entry becomes 1 .

- If the $(i, j)$ entry in the SSIM is $X$, then the $(i, j)$ entry in the reachability matrix becomes 1 and the $(j, i)$ entry also becomes 1

- If the $(i, j)$ entry in the SSIM is $O$, then the $(i, j)$ entry in the reachability matrix becomes 0 and the $(j, i)$ entry also becomes 0 .

In the final reachability matrix, the driving power and the dependence of each risk-mitigation were also shown. The driving power for each risk-mitigation was the total number of risk mitigation (including it) which it may impact. Dependence of risk mitigation was the total number of risk mitigations (including it) which may be impacting on it. These driving powers and dependencies will be used in the MIC-MAC (Matrice d'Impact Croisés - Multiplication Appliqué à un Classement or Matrix of Cross Impact Multiplications Applied to Classification) analysis (Godet 1986), where the barriers will be classified into four groups - autonomous, dependent, linkage, and independent (driver) risk mitigations.

Based on the relationship given in the reachability matrix, a directed graph was drawn and the transitive links were removed then the resultant digraph was converted into an ISM. The ISM then was reviewed to check for conceptual inconsistency and necessary modifications are made to clarify the relationships among risk mitigations.

\subsection{Questionnaire Design and Data Collection}

The main data were collected from May 2009 to July 2010 then the additional related data were gathered up to December 2012. Initial study was carried out with experts to determine the initial criteria pool by a thorough literature review and doing qualitative interviews. A comprehensive literature review was conducted to ground the development of the initial pool of items. Experts then reviewed the initial pool of criteria and gave feedback regarding criteria relevance, clarity, conciseness, and sufficiency in tapping the constructs.

Experts were people who represent members of chain or those who have expertise in mangosteen business. A purposive sample was used to ensure the representation of experts within each member of the supply chain. In this research, 12 experts were selected from which 7 represent farmers group, 1 represents cooperative of farmers, AlIhsan, 1 represents exporter, and 1 represents Center for Tropical Fruit Studies, 1 represents HPSP, and 1 represents Agricultural Office of Bogor District.

The hierarchy of risks was made according to discussion with experts and a review of literature. Risks were identified through 4 levels of point of view: the objective of the analysis, goals of the whole supply chain (integrated by considering the goals of each member), sources of risks, and potential risks. The items of each level were then incorporated into a questionnaire.

The questionnaire consisted of two sections: one referring to supply chain risks and one referring to risk mitigations. Fuzzy AHP survey aimed at evaluating the comparability of the perceived criteria for supply chain risks. Risks mitigations then were identified according to the supply chain risks and a review of literature on risks mitigations, ISM survey then was conducted which aimed at understanding the complex relationships among risks mitigations. In order to help accomplishing these aims, questionnaires were designed for data collection and the format was synthesized with reference to AHP matrix and ISM matrix.

\section{RESULTS AND DISCUSSION}

\subsection{Potential Risks in Supply Chain of Mangosteen}

The objective of the analysis was to identify the risks of supply chain of mangosteen in Bogor District. The goal of the chain was considered to be the next level of the hierarchy in identifying the risks. According to the members of mangosteen supply chain in Bogor District, the whole chain goals were: (1) Value added improvement, (2) Market access improvement, (3) Operational efficiency improvement, (4) Financial building, (5) Information access improvement, (6) Risk reduction, and (7) Sustainable partnership maintenance

Goals of mangosteen supply chain can be achieved if the risks of supply chain can be mitigated well according to the resource of the risks. Hence, the next levels to be considered of the hierarchy in identifying the risks were risks source and potential risks in each source. In detail, the elements of those both levels are (1) production which has uncertainty of weather as well as uncertainty of production quality and quantity as potential risks, (2) market of which uncertainty of price and uncertainty of demand are considered as potential risks, (3) institutional which considers government policy and business relationship between partners as potential risks, (4) human or personal of which is comprised of variation of personal skill and knowledge as well as personal welfare (concerning of healthy and social life or the person in the chain) as potential risks, and (5) financial which considers fluctuation of money exchange rate and uncertainty of return on investment as potential risks.

The result of potential risk analysis using fuzzy AHP method based on experts judgements expressed in a ninepoint ratio scale is shown in Figure 4 with consistency ratio below 0.1. According to mangosteen experts judgement, the main goal of mangosteen supply chain in Bogor District, West Java Province, Indonesia was financial building with degree of importance was 0.200 . Financial building was an essential prerequisite for the ultimate benefit of the emerging supply chain. Without financial building, the chain would lack of financial source in running the business process which linkages to the sustainability of the chain.

Partnership sustainability had the least degree of importance $(=0.088)$ as goal of the chain. The members of the chain hadn't known each other since the chain was an emerging supply chain. The members of the chain weren't sure whether they will continue their partnership in the chain. They might maintain their partnership in the chain if they could achieve the other more important goals by being the member of the chain. Hence, the member of the chain 
only gave a low degree of importance for partnership sustainability.

In achieving the goals, this supply chain of mangosteen had to face some risks. Institutional was the highest degree of importance $(=0.261)$ of risk sources. Business relationship between partners was potential risk from institutional risk source which was considered to have higher degree of importance $(=0.639)$ than that of government policy $(=0.361)$. As an emerging supply chain, introduction of a new system to the members of chain usually requires special effort. Members will often face some conflicts due to distrust with partners, the incompatibility of character and ethics in working together, discrepancies in business development, inequality interests and goals, as well as resources that are not mutually supportive partners.
Financial also had the same degree of importance as that of institutional. Some farmers as the member of the chain used to sell mangosteen to buyers who paid them before the mangosteen fruits being harvested although the buyers bought the mangosteen in cheap price. Farmers felt that their investment had already returned when the buyers paid them before mangosteen fruits being harvested. In this supply chain, Al-Ihsan paid farmers after the farmers delivered the fruits to Al-Ihsan and exporter paid after sorting and grading process of fruits delivered by Al-Ihsan. The farmers sometimes broke the agreement with Al-Ihsan because they need their investment in mangosteen business return faster although in fact Al-Ihsan gave farmers higher revenue by buying the fruits in higher price than that bought by other buyers.

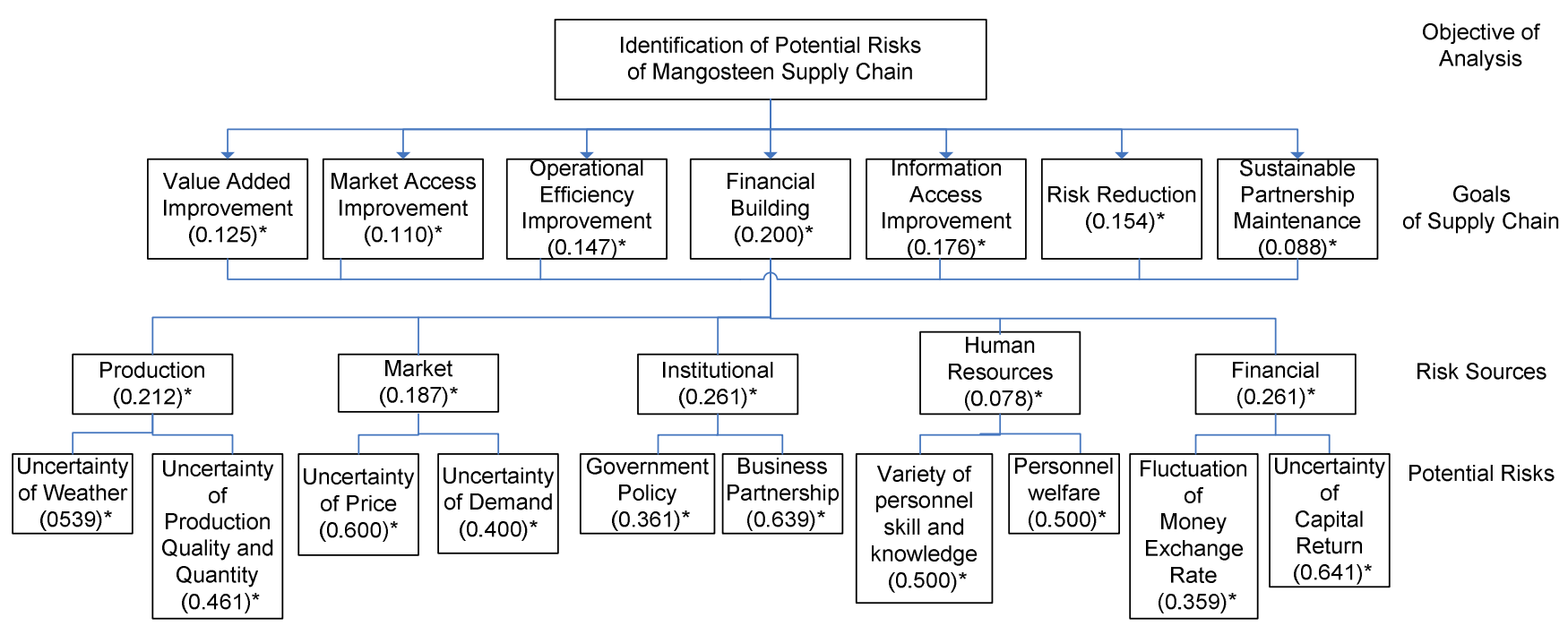

*Weight of degree of importance which was measured using Fuzzy AHP method

Figure 4. AHP Structure of Potential Risks Identification

Al-Ihsan as the driving force of the chain should compete to the other buyers in buying mangosteen from the farmers to meet demand of the customer. If farmers sold mangosteen fruits to other buyers which were not members of the chain, the demand of the fruits might not be able to be fulfilled. Hence, financial also had a high degree of importance $(=0.261)$ as risk sources and potential risk of that sources which had high degree of importance $(=0.641)$ was uncertainty of return on investment.

Human was the risk source which had the smallest degree of importance $(=0.078)$ in the supply chain of mangosteen in Bogor District although this chain still needs improvement in skill and knowledge of the human resource. The supporter of the chain (Center for Tropical Fruit Studies, Bogor Agricultural University, HPSP and Agricultural Office of Bogor District will help in handling the variation of personal skill and knowledge by giving some training. The welfare of the personal in the chain (concerning the health and social life of the human resource) also didn't consider being potential risk which had a high degree of importance because most of the person in the chain was still young and strong enough to run the mangosteen business. The average of the farmers' age was 48 years old (Agricultural and Forestry Office 2007).

\subsection{Risk Mitigation in Supply Chain of Mangosteen}

In order to reduce the extent of exposure to the risks and / or the likelihood of their occurrence, the members of the supply chain should neutralize the risks by preparing some risk mitigations strategies. According to the respondents who were expert in mangosteen business, risk mitigations which could be considered for reducing the risks in supply chain of mangosteen in Bogor District were as follow:

1. Vertical integration

Vertical integration refers to a firms' ownership of vertically related activities. The greater the firms' ownership and control over successive stages of the value chain of its product, the greater it is vertically integrated (Khoi 2007). Vertical integration of mangosteen business was necessary to take affirmative action on the risk mitigation. Vertical integration lessens the risk of cost increases, disruption of critical material supplies, and quality problems. It has to do with the control over successive stages of the entire production process. Vertical integration also offers economies of combined operations such as sales, purchasing, and 
overhead allocations. By lowering manufacturing costs and ensuring a stable supply of critical components, vertical integrators remove some of the risk in the businesses of supply chain member (Grabhan et al., 2005). The internal solution by vertically integrated supply chain may achieve the highest level of risk avoidance if all processes are run properly (Mau and Mau 2009).

\section{Horizontal coordination}

Horizontal coordination is coordination mechanisms for firms e.g. belonging to different supply chains. The main purpose of horizontal coordination is to improve efficiency through the exploitation of economies of scale (Boute and Lambrecht, 2007).

Horizontal coordination may facilitate organizations to forecast disorder. In fact, without horizontal coordination companies may face the risk of long lead time and finally supply chain disturbances (Mehmood et al., 2010).

The horizontal relationships, between parties engaged in similar activities, that is, located at the same stage of the value chain are different in nature to vertical relationships. The vertical dimension deals with the flow of products from suppliers to users, while on the horizontal dimension similar, competing products (substitutes in consumption) are pooled to share a common resource of production or distribution, in a scale strategy. When comparing relationships on the two dimensions there will be different strengths, in terms of size (volume), type, frequency, and durability of exchange, and in terms of force of control (Wood 2010).

\section{Trust building}

It has been argued that issues of trust and risk can be significantly more important in supply chain relationships because supply chain relationships often involve a higher degree of interdependency between competitors (La Londe 2002). One of the key factors that are attributed to the successful supply chain relationship is trust. Building partnership trust is at the heart of managing risk and prerequisite in supply chain (Laeequddin et al., 2009).

4. Establishing price and quality contract between Al-Ihsan and farmers

Price changes at one stage in the supply chain of agricultural commodities are not necessarily transmitted to other stages. Farmer accuses retail companies of abusing their market power to increase profit margins. Farmers consequently receive too little and consumers pay too much (Bunte 2006). On the other hand, a lot of evidences show that small farmers are not able to meet the strict quality requirement of retail companies. One possible mechanism for improving the livelihood of rural smallholders is to link the farmers to the market and to provide them with the benefits of economic liberalization via the contract farming (Arumugam et al., 2010).

Contract farming can be defined as a system for the production and supply of land based and allied produce by farmers under advance contracts, the essence of such arrangements being a commitment to provide an agricultural commodity of a type, at a specified time, price, and in specified quantity to a known buyer. Contract gives farmer an access to additional sources of capital and a more certain price by shifting part of the risk of adverse price movement to the buyer. Farmers also get an access to new technology and inputs through contracts which otherwise may be outside their reach. Establishing price and quality contract between Al-Ihsan and farmers is an intermediary contract faming model where a middleman is involved between the exporter and the farmer (Singh 2007).

5. Establishing price and quality contract between Al-Ihsan and exporter

According Singh (2007), establishing price and quality contract between Al-Ihsan and farmers is an intermediary contract faming model where a middleman is involved between the exporter and the farmer. The effectiveness of contract farming can be considered from the perspective of the farmer and of the exporter. Contract farming is simple pre-harvest agreements where the exporter commits to provide an export market for the farmer. Usually, there are stipulated the conditions regarding price, quantity, quality, and timing. The farmer reduces the market and price risks and transfers it to the exporter without losing the control of the production process. The farmer must adopt specific growing practices, input regimes and post-harvest management practices under the technical supervision of Al-Ihsan. Contract farming is mainly a way to distribute the activities in the supply chain and the corresponding risk between the exporter and farmers. The farmer bears most of the production risks and the exporter most of the processing and marketing risks. The exact allocation of risk depends on the specifications of the contract.

6. Advocating to government to improve facilitation of soft loans for agricultural business.

Most agricultural support services are currently provided under the umbrella of associations / cooperation. Provision of services is constrained by a number of factors including difficulties of accessing agricultural loans. The plea for accessing agricultural loans have been largely ignored by the commercial banks probably because of the perceived risk in agricultural financing and the negative consequences of volatile agricultural market (Davies, 2009). Associations / cooperation should advocate the government to facilitate increased investment in agriculture by strengthening the financial capacity of state-owned agricultural banks to grant soft-loans and pleading with the private commercial banks to extend low-interest loan facilities to large-scale and small-scale farmers.

Understanding and quantifying the complex and extensive interrelationships between risk mitigation will help the supply chain management to focus on those key risk mitigations for effective risk minimization in supply chain of mangosteen in Bogor District. Interpretive Structural Modeling (ISM) was used to find out the interaction among the risk mitigations with the steps as follows: 
1. The risk mitigations were compared in a relation matrix, using a contextual relationship, which is mostly a verb or a verb phrase. Typical generic verbs are "influences" or "causes" and verb phrase are "leads to" "is more important than" (Kanungo and Jain 2009). In this research, experts were consulted in identifying the nature of contextual relationship of type "influences" among the risk mitigations

2. Based on this contextual relationship, an initial Structural Self Interaction Matrix (SSIM) was developed which is shown in Table 1.

Table 1. Initial SSIM for Risk Mitigations in Emerging Supply Chain of Mangosteen in Bogor District

\begin{tabular}{|c|c|c|c|c|c|c|}
\hline 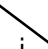 & 1 & 2 & 3 & 4 & 5 & 6 \\
\hline 1 & & A & $A$ & $X$ & $X$ & V \\
\hline 2 & & & $x$ & V & V & V \\
\hline 3 & & & & V & V & V \\
\hline 4 & & & & & $X$ & V \\
\hline 5 & & & & & & V \\
\hline 6 & & & & & & \\
\hline
\end{tabular}

1-6: risk mitigations

(1: Vertical integration;

2: Horizontal coordination;

3: Trust building;

4: Establishing price and quality contract between AlIhsan and farmers;

5: Establishing price and quality contract between AlIhsan and exporter;

6: Advocating to government to improve facilitation of soft

loans for agricultural business)

$\mathrm{V}$ : risk mitigation i will influence risk mitigation $\mathrm{j}$, but risk mitigation $\mathrm{j}$ will not influence risk mitigation $\mathrm{i}$

$A$ : risk mitigation $\mathrm{j}$ will influence risk mitigation $\mathrm{i}$, but risk mitigation $\mathrm{i}$ will not influence risk mitigation $\mathrm{j}$

$\mathrm{X}$ : risk mitigation $\mathrm{i}$ and $\mathrm{j}$ will influence each other

3 . Based on the adjacent matrix, a reachability matrix (a binary matrix which elements are 0 or 1 ), that reflects the directed relationship between the risk mitigations, was created then the matrix was checked for transitivity.

4. Following the rules for the substitution of 1's and 0's and after incorporating the transitivity, the final reachability matrix is shown in Table 2 .

Table 2. Reachability Matrix for Risk Mitigations in Emerging Supply Chain of Mangosteen in Bogor District

\begin{tabular}{|c|c|c|c|c|c|c|}
\hline 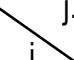 & 1 & 2 & 3 & 4 & 5 & 6 \\
\hline 1 & 1 & 0 & 0 & 1 & 1 & 1 \\
\hline 2 & 1 & 1 & 1 & 1 & 1 & 1 \\
\hline 3 & 1 & 1 & 1 & 1 & 1 & 1 \\
\hline 4 & 1 & 0 & 0 & 1 & 1 & 1 \\
\hline 5 & 1 & 0 & 0 & 1 & 1 & 1 \\
\hline 6 & 0 & 0 & 0 & 0 & 0 & 1 \\
\hline
\end{tabular}

5. Once the transformation from SSIM to initial reachability matrix had been carried out according to the rules, any transitive links that may exist between different risk mitigations are investigated. In the final reachability matrix, the driving power and the dependence of each risk-mitigation were also shown (Table 3).

Table 3. Reachability Matrix Interpretation for Risk Mitigations in Emerging Supply Chain of Mangosteen in Bogor District

\begin{tabular}{|c|c|c|c|c|c|c|c|c|}
\hline & 1 & 2 & 3 & 4 & 5 & 6 & $D P$ & $R$ \\
\hline 1 & 1 & 0 & 0 & 1 & 1 & 1 & 4 & 2 \\
\hline 2 & 1 & 1 & 1 & 1 & 1 & 1 & 6 & 1 \\
\hline 3 & 1 & 1 & 1 & 1 & 1 & 1 & 6 & 1 \\
\hline 4 & 1 & 0 & 0 & 1 & 1 & 1 & 4 & 2 \\
\hline 5 & 1 & 0 & 0 & 1 & 1 & 1 & 4 & 2 \\
\hline 6 & 0 & 0 & 0 & 0 & 0 & 1 & 1 & 3 \\
\hline$D$ & 5 & 2 & 2 & 5 & 5 & 6 & & \\
\hline$R$ & 2 & 3 & 3 & 2 & 2 & 1 & & \\
\hline
\end{tabular}

6. Driving power - Dependence diagram (Figure 5) then was used in the MIC-MAC analysis to analyze the driving power and the dependence of the risk mitigations.

7. In order to create structural models (Figure 6), the reachability matrix was decomposed into different levels which provided a multilevel ISM. From the final reachability matrix, the reachability and the antecedent set for each risk mitigation can be found (Faisal, 2010). The reachability set includes risk mitigation itself and others which it may help to influence, similarly the antecedent set consists of risk mitigation itself and the other risk mitigations which help in influencing it. Then, the intersection of these sets is derived for all risk mitigations. The risk mitigation for which the reachability and intersection sets are same is the toplevel risk mitigation in the ISM hierarchy.

For the risk mitigations identified in this research, the ISM model depicted that to mitigate risk in a supply chain it was imperative to develop horizontal coordination and trust among supply chain members. Horizontal coordination and trust building will influence each other to support vertical integration, establishing price and quality contract between Al-Ihsan and farmers, as well as establishing price and quality contract between Al-Ihsan and exporter

According to the DP-D Diagram (Figure 5), horizontal coordination and trust building had strong driving power to influence the other risk mitigations, but weak dependence on others risk mitigations in supply chain of mangosteen in Bogor District. It indicated that management of the supply chain should pay more attention to horizontal coordination and trust building in mitigating the risks in the supply chain. It would be much easier for the chain to do vertical integration, establish price and quality contract between AlIhsan and farmers, as well as establish price and quality contract between Al-Ihsan and exporter if the supply chain management already developed horizontal collaboration and trust building. 


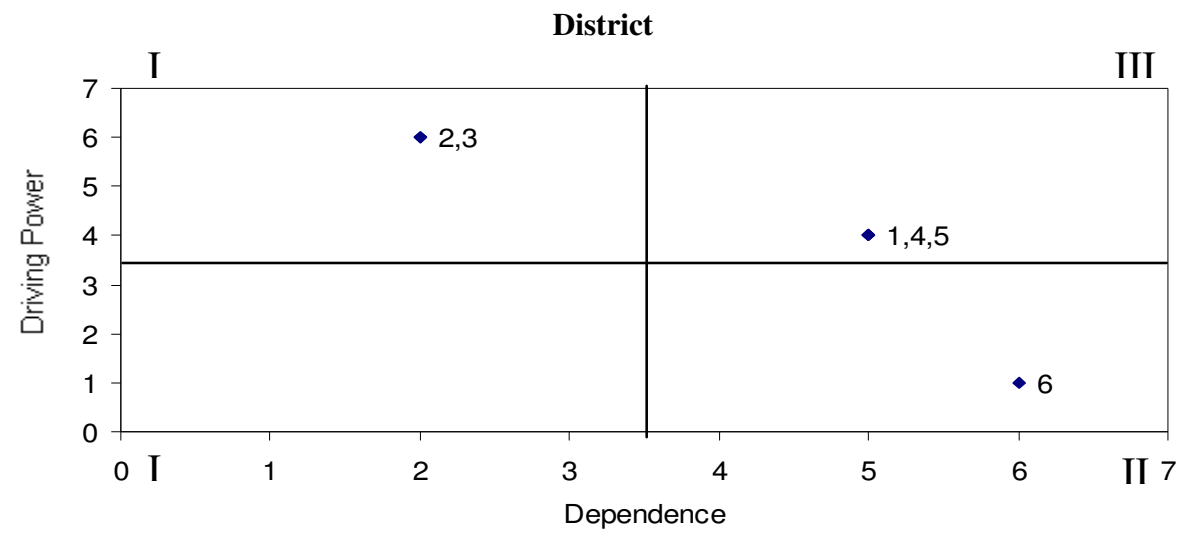
I : Autonomous
II : Dependent
III : Linkage
IV : Independent

Figure 5. Driving Power - Dependence (DP-D) Diagram for Risk Mitigations in Emerging Supply Chain of Mangosteen in Bogor

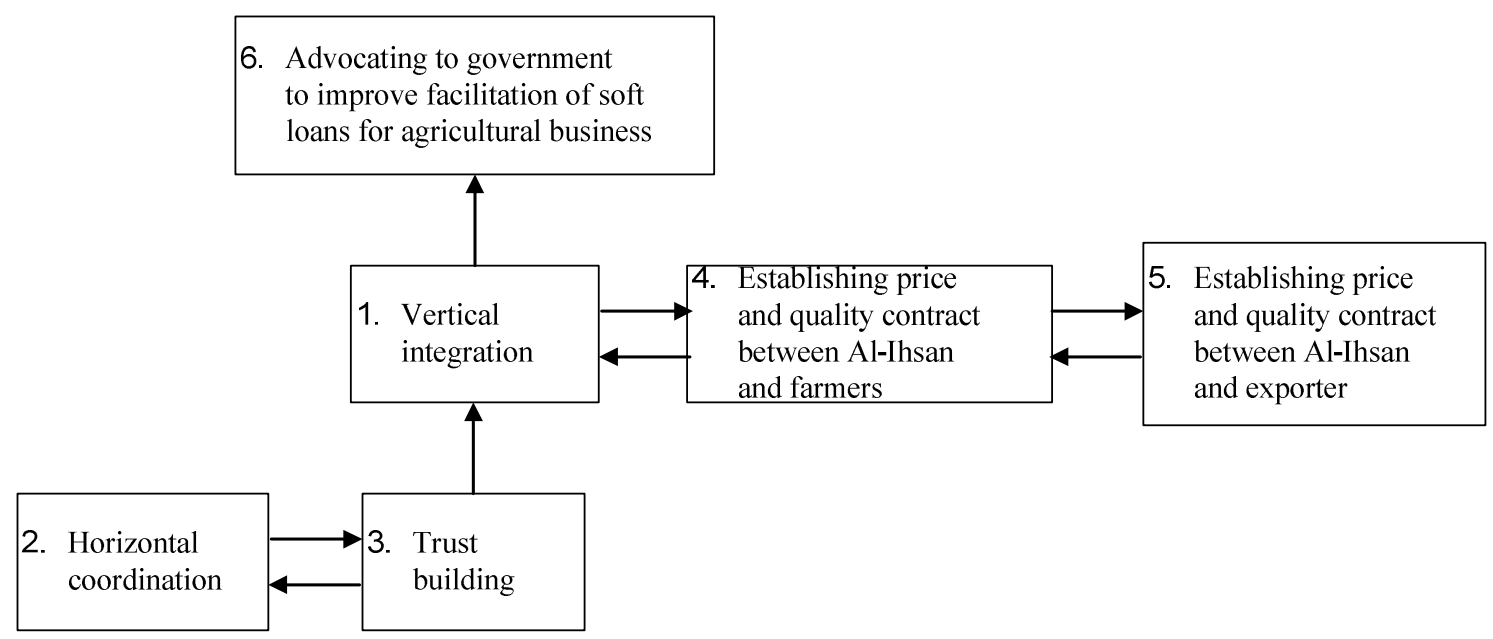

Figure 6. Structural Model for Risk Mitigations in Emerging Supply Chain of Mangosteen in Bogor District

Business relationship between partners as potential risk in supply chain of mangosteen in Bogor District also can be countered by vertical integration, establishing price and quality contract between Al-Ihsan and farmers, as well as establishing price and quality contract between Al-Ihsan and exporter. Those risk mitigations were in third cluster which have strong driving power and also strong dependence. It indicated that vertical integration, establishing price and quality contract between Al-Ihsan and farmers, as well as establishing price and quality contract between Al-Ihsan and exporter were unstable. Any action on those risk mitigations will have an effect on others and also a feedback on themselves. This was quite expected as vertical integration, establishing price and quality contract between Al-Ihsan and farmers, as well as establishing price and quality contract between Al-Ihsan and exporter for managing risk will impact advocating to government to improve facilitation of soft loans for agricultural business. Vertical integration and contracts between partners will assure government that the chain will be run well supported by soft loans.

Advocating to government to improve facilitation of soft loans for agricultural business had the least driving power and had highest dependence as well as forms the top most level in the ISM hierarchy. Its strong dependence indicated that it required all the other risk mitigations to come together so as to make it counter risks. Advocating to government to improve facilitation of soft loans for agricultural business was important because that risk mitigation were finally required by the supply chain to effectively mitigate risk in the supply chain of mangosteen in Bogor District.

The result of the research can be generalized to other emerging supply chain of agricultural commodities which has relatively same of overall operational environment and setting of the chain, but the model will require some modifications as experts for other supply chain may slightly differ in their opinion about the contextual relationships among the risk mitigations. A major contribution of the research lies in imposing direction to various enablers of risk mitigation which would help the decision makers in the chain to better utilize their scarce resources for risk minimization in the supply chain. 


\section{CONCLUSIONS AND FUTURE OUTLOOK}

The decision maker of the supply chain tended to think that the only need to counter risk in the supply chain was some sort of plan that would be put into place once the supply chain was posed with that risk, but the result of the research showed that to develop these plans from a supply chain perspective would require a careful consideration of horizontal coordination, trust building, vertical integration, establishing price and quality contract between Al-Ihsan and farmers, establishing price and quality contract between AlIhsan and exporter, as well as advocating to government to improve facilitation of soft loans for agricultural business as a strategic nature. The results of this study gave useful insights to decision makers to prioritize different risks sources of mangosteen supply chain in Bogor District, West Java Province, Indonesia from the point of view of some criteria. This was necessary so that the supply chain management can determine the risks mitigation according to the risks sources. Risks should be monitored and decisions about mitigation strategies should be made based on the goal of the chain and the risks sources. Finally, a further risk was related to the change management activities.

Although emerging supply chain of mangosteen gave some benefits to the farmers as the member of supply chain such as market guarantee and better price of mangosteen, sustainability of partnership will be the threat to the chain due to the weak economy and financial ability of farmers. The loyalty of the farmers as the member of the chain were still based on the short-term financial benefits meanwhile the farmers would get long-term benefits as loyal members of the supply chain. The cooperative of farmers as the initiator of the chain also had a weak bargaining position because there was only one exporter as the buyer of mangosteen in the chain. This condition will be worse due to the limited financial source of the farmer cooperative.

Horizontal coordination and trust building had been viewed by the experts as essential preconditions for advocating to government to improve facilitation of soft loans which were needed by cooperative of farmers for buying mangosteen in cash so that the farmers will get more certain return on investment. The managerial implication here was that mangosteen supply chain management in Bogor District should act positively toward government policy in order to mitigate institutional and financial risks, i.e. business relationship between partners and uncertainty of return on investment, as the main risks sources of the mangosteen supply chain in Bogor District by strengthening horizontal coordination and trust building between the members of the chain.

Fuzzy AHP and ISM are subjective methods with the main data are collected from experts judgements which are not necessary to involve a large sample. Those methods are suitable for analyzing the risks sources and the mitigation strategies for those risks in the supply chain of mangosteen in Bogor District which has limitation in data availability because the chain was just built. Those methods would rather rely on the opinion of experts than the sample size of the data. The ability of researchers to capture information from expert opinion and the selection of the experts as respondents are critical in the application of AHP and ISM. The major advantage of this approach is that it helped them think in a comprehensive and detailed manner, while allowing them to categorize the various issues.

Future research extension could examine the effect of changes in experts' preferences. For example, if the final ranking of alternatives were changed greatly with slight variations in input values, it might suggest further research to obtain more accurate estimates. Sensitivity analysis can also be used in assessing the impact of alternative scenarios.

\section{REFERENCES}

Agricultural and Forestry Office (2007), Profile of Mangosteen in Bogor district. Potential Investment for Horticulture, Agricultural and Forestry Office, Bogor, Indonesia, Agricultural and Forestry Office. Bogor, Indonesia.

Ahsan, D.A. and Roth, E. (2009), How to Handle Risks in Mussel Farming Business? An Experience from Denmark, presented at VII International PENSA Conference, Sao Paulo, Brazil.

Anantatmula, V. and Kanungo, S. (2005), Establishing and Structuring Criteria for Measuring Knowledge Management, Proceedings of the $38^{\text {th }}$ Hawaii International Conference on System Sciences, IEEE, pp. 1-11.

Arumugam, M., Fatimah, M. A., Chiew, E. F. C., and Zainalabidin, M. (2010), Supply Chain Analysis of Fresh Fruits and Vegetables (FFV): Prospects of Contract Farming, Agricultural Economics, 56 (9), pp. 435-442.

Ayağ, Z. and Özdemir, R.G. (2006), A fuzzy AHP Approach to Evaluating Machine Tool Alternatives, Journal of Intelligent Manufacturing, 17 (2), pp. 179190.

Bailey, W.C., Norina, L. and Cassavant, K. (2002), The Use of Supply Chain. Management to Increase Exports of Agricultural Products. Proceedings of the $5^{\text {th }}$ International Conference on Chain and Network in Agribusiness and the Food Industry, J.H. Trienekens and S. W. F. Omta (Eds.), Wageningen, The Netherlands, pp. 410-421.

Boute, R. and Lambrecht, M. (2007), Altruistic Behaviour in Supply Chain Management, Tijdschrift voor Economie en Management, 52 (3), pp. 499-514.

Bouyssou, D., Marchant, T. , Pirlot, M., Perny, P. , Tsoukias , A., and Vincke, P. (2000), Evaluation and Decision Models: A Critical Perspective, Kluwer, Boston.

Bunte, F. (2006), Pricing and Performance in Agri-Food Supply Chains, In C. J. M. Ondersteijn, J. H. M. Wijnands, R.B. M. Huirne, O. van Kooten (Ed.), Quantifying the Agri-Food Supply Chain, Springer Science Business Media, Netherlands.

Cheng, E.W.L and Li, H. (2002), Construction Partnering Process and Associated Critical Success Factors: Quantitative Investigation, Journal of Management in Engineering, 18 (4), pp. 194-202. 
Davies, A. E. (2009), Food Security Initiatives in Nigeria: Prospects and Challenges, Journal of Sustainable Development in Africa, 11 (1), pp. 186-202.

Deloitte and Touche, Supply Chain Risk Management, http://www.deloitte.com/dtt/cda/doc/content/nl_eng_br ochure_supply_chain_risk_management_070704x(1).p df, Accessed November 27, 2008.

Dimyati, A. and Muharam, A. (2006), Supply Chain Management of Mangosteen in West Java: an Attempt to Establish a Collaborative Model, Proceeding I International Symposium on Supply Chains Economics, Batt, P.J. (Ed.), Acta Horticulturae No. 699, ISHS, pp. 151-157.

Directorate General of Horticulture, (2008), Meeting Report: Pilot Laboratory of Mangosteen Area, Agricultural Ministry, Indonesia.

Directorate General of Horticulture, (2009), Description of Macro Performance of Horticulture, Agricultural Ministry, Indonesia.

Faisal, M.N. (2010), Analysing the Barriers to Corporate Social Responsibility in Supply Chains: An Interpretive Structural Modeling Approach, International Journal of Logistics Research and Applications, 13 (3), pp. 179-195.

Godet, M. (1986), Introduction to La Prospective: Seven Key Ideas and One Scenario Method, Futures, 18 (2), pp. 134-157.

Gorvett, R. and Liu, N. (2006), Interpretive Structural Modeling of Interactive Risks, presented at Enterprise Risk Management Symposium, Society of Actuaries, Chicago, IL.

Grabhan, M., Pavese, A., Hutton, R., and Creecy, H. (2005), Overcoming The Pressures of Modern Horticulture. IREC Farmers' Newsletter, Irrigation Research \& Extension Committee, Murrumbidgee Valley of New South Wales, 170 (Spring).

Hardaker, J.B., Huirne, R.B.M., Anderson, J.R., and Lien, G. (2004), Coping with Risk in Agriculture, CAB International, Wallingford, UK.

Hart, V., Kavallari, A., and Schmitz, M. (2007), Supply Chain Analysis of Fresh Fruit and Vegetables in Germany, Market and Trade Policies for the Mediterranean Agriculture: The Case of Fruit / Vegetables and Olive Oil, MEDFROL Project.

Harwood, Heifner, J. R., Coble, K., Perry, J., and Somwaru, A. (1999), Managing Risk in Farming: Concepts, Research, and Analysis, Economics Research Service, U.S. Department of Agriculture, Washington D.C.

International Organization for Standardization, (2002), ISO/IEC Guide 73 Risk management Vocabulary Guidelines for Use in Standards, International Organization for Standardization.

Kanungo, S. and Jain, V. (2009), Using Interpretive Structural Modeling to Uncover Shared Mental Models in IS Research, presented at European Conference on Information Systems, Verona, Italy.

Kersten W, Böger, M., Hohrath, P., and Späth, H. (2006) Supply Chain Risk Management: Development of a Theoretical and Empirical Framework, In: Kersten W and Blecker, T. (Ed.), Managing Risks in Supply
Chains: How to Build Reliable Collaboration in Logistics, Berlin.

Khoi, L. N. D. (2007), Vertical Integration as An Alternative Governance Structure of Value Chain Quality Management: The Case of Pangasius Industry in the Mekong River Delta, Vietnam, CAS Discussion Paper, Center of ASEAN Studies, 55.

La Londe, B. (2002), Who Can You Trust These Days?, Supply Chain Management Review, May-June, pp. 910.

Laeequddin, M., Sardana, G. D., Sahay, B. S., Waheed, K. A., and Sahay, V. (2009), Supply Chain Partners Trust Building Process Through Risk Evaluation: The Perspective of UAE Packaged Food Industry, Supply Chain Management: An International Journal, 14 (4), pp. 280-290.

Lee, A. R. (1999), Application of Modified Fuzzy AHP Method to Analyze Bolting Sequence of Structural Joints, Dissertation, UMI Dissertation Services, A Bell \& Howell Company.

Leung, L. C., and Chao, D. (2000), On Consistency and Ranking of Alternatives in Fuzzy AHP, European Journal of Operational Research, 124 (1), pp. 102113.

Marimin, Feifi, D., Martini, S., Astuti, R., Suharjito, and Hidayat, S. (2010), Added Value and Performance Analyses of Edamame Soybean Supply Chain: A Case Study, Operations and Supply Chain Management, 3 (3), pp. 148-162.

Mau, N. and Mau, M., (2009), Securing Global Foods Distribution Networks, In G. A. Zsidisin and B. Ritchie (Eds.), Supply Chain Risk: A Handbook of Assessment Management and Performance, Springer.

Mehmood, W., Liaqat, Y., Iftikhar, N., and Hassan, R. S. (2010), Managing Supply Chain Risks in Fresh Food Items: A Case Study on Makro-Habib Pakistan Limited-A Wholesale Chain in Pakistan, Master Thesis, School of Business and Economics, Master Program in Business Process \& Supply Chain Management, Linnaeus University, Växjö.

Meuwissen, M. P. M., Huirne, R. B. M., and Hardaker, J. B. (2001), Risk and Risk Management: An Empirical Analysis of Dutch Livestock Farmers, Livestock Production Science, 69 (1), pp. 45-53.

Moeinzadeh, P. and Hajfathaliha, A. (2009), A Combined Fuzzy Decision Making Approach to Supply Chain Risk Assessment, World Academy of Science, Engineering and Technology, 60, pp. 519-535.

Muralidharan, C., Anantharaman, N., and Deshmukh, S. G. (2002), A Multicriteria Group Decision Making Model for Supplier Rating, Journal of Supply Chain Management, 38 (4), pp. 22-33.

Özdağoğlu, A. and Özdağoğlu, G. (2007), Comparison of AHP and Fuzzy AHP for The Multicriteria Decision Making Processes with Linguistic Evaluations, Ístanbul Ticaret Üniversitesi Fen Bilimleri Dergisi, 6 (11), pp. 65-85.

Saaty, T. L. (1981), The Analytic Hierarchy Process, McGraw-Hill, New York. 
Saaty, T.L. (1989), Decision Making, Scaling, and Number Crunching, Decision Science, 20 (2), pp.404-409.

Singh, S. (2007), Leveraging Contract Farming for Improving Supply Chain Efficiency in India: Some Innovative and Successful Models, Presented at the $3^{\text {rd }}$ International Conference on Linking Markets and Farmers: Exploring Leading Practices to Foster Economic Growth in Rural India. New Delhi.

Siquera, K. B., Da Silva, C. A. B., and Aguiar, D. R. D. (2008), Viability of Introducing Milk Futures Contracts in Brazil: A Multiple Criteria Decision Analysis, 24 (4), pp. 491-509.

Spekman R.E. and Davis, E. W. (2004), Risky Business: Expanding the Discussion on Risk and the Extended Enterprise, International Journal of Physical Distribution \& Logistics Management, 34 (5), pp. 414433.

Supply-Chain Council. 2008. SCOR. Supply Chain Operations Reference Model. Version 9.0. The Supply Chain Council, Inc. Canada.

Szèp, K., Sidlovits, D., Bálint, A., and Kovács, C. (2000), Risk Management in Horticultural Farms of Hungary, Proceeding XIV International Symposium on
Hortucultural Economics, Acta Horticulturae No. 536, pp. 311-320.

Taha, H. A. (2003), Operations Research, Pearson Education Inc., Fayetteville.

Tang, C. S. (2006), Perspective in Supply Chain Risk Management, International Journal of Production Economics, 103 (2), pp. 451-488.

Taylor, B. W. (2004), Introduction to Management Science, Pearson Education Inc., New Jersey.

Vorst, J. G. A. J. van der, (2000), Effective Foody Supply Chains, Generating, Modelling, and Evaluating Supply Chain Scenarios. PhD Thesis. Wageningen University.

Vorst, J.G.A.J. van der, (2006), Performance Measurement in Agrifood Supply Chain Networks: An Overview, In C. J. M. Ondersteijn, J. H. M. Wijnands, R. B. M. Huirne, O. van Kooten (Ed.), Quantifying the Agri-Food Supply Chain, Springer Science Business Media, Netherlands.

Wood, L.C. (2010), Effective Horizontal Coordination in Coopetitive Clusters: Developing The Required Attributes for Supply Chain Management, $8^{\text {th }}$ World Congress 2010, Participatory Action Research and Action Learning, $6^{\text {th }}-9^{\text {th }}$ September, Melbourne Australia.

Zadeh, L.A. (1994), Fuzzy Logic, Neural Network, and Soft Computing, Communication of the ACM, 37 (3), pp.77-84.

\begin{abstract}
Retno Astuti (retno_astuti@ub.ac.id; retno_astuti_triharso@yahoo.com) is a lecturer at Department of Agroindustrial Technology, Faculty of Agricultural Technology, University of Brawijaya, Malang, Indonesia. She has teaching and research experiences in the fields of Operation Research, Operational Management, and Supply Chain Management. She earned her graduate degree in Agroindustrial Technology from Gadjah Mada University, Yogyakarta, Indonesia, Master degree in Industrial Engineering and Management from Bandung Institute of Technology, Bandung, Indonesia, and Doctoral degree in Agroindustrial Technology, Post graduate School, Bogor Agricultural University, Bogor, Indonesia.
\end{abstract}

Marimin (marimin@ipb.ac.id; marimin_07@yahoo.com) is a Professor of System Engineering and Decision Science at Department of Agroindustrial Technology, Bogor Agricultural University (IPB), Bogor, Indonesia. He has over 25 years of teaching and research experience in the fields of Decision Analysis, Quantitative Business Analysis, Intelligent Decision Support and Expert System, and Supply Chain Management. He has authored many papers published at international journals such as J. System, Man and Cybernetics of Institute of Electrical and Electronic Engineer (IEEE) and J. Intelligent and Fuzzy Systems. He earned his B.Sc. Honour in Industrial Engineering from IPB, a M.Sc. in Computer Science from University of Western Ontario, Canada and a Ph.D. in System Engineering from Osaka University, Japan. He is an active member of IEEE. His research interests are in soft system methodology, computational intelligence, green supply chain management and their application to agroindustry.

Machfud (machfud@ipb.ac.id; machfud_yassin@yahoo.com) is an Associate Professor of Agroindustrial System Engineering at Department of Agroindustrial Technology, Bogor Agricultural University (IPB), Bogor, Indonesia. He has over 34 years of teaching and research experience in the fields of Agroindustrial Development, Production Planning and Inventory Control, and Supply Chain Management. He has authored many papers published at journals such as Journal of Agroindustrial Technology. He earned his B.Sc. Honour in Agricultural Product Technology from IPB, a M.Sc. in Industrial Engineering and Management of Bandung Institute of Technology (ITB), and Dr. Degree in Agroindustrial Technology from IPB.

Yandra Arkeman was born in Payakumbuh (West Sumatera) in September $14^{\text {th }} 1965$. He graduated from Department of Agroindustrial Technology, Bogor Agricultural University in 1989 and received M. Eng Ph.D degree in Manufacturing System Engineering from University of South Australia in 1996 and 2000 consecutively. He conducted post- doctoral research in Computer Science and Agroindustrial Informatics in Japan (2004-2006) and USA (2009/2010). He is member of Society of Manufacturing Engineers (SME), Institute of Industrial Engineers (IIE) and International Society of System Science (ISSS). His biography is included in Who's Who in Science and Engineering 1998/1999. He is a lecturer in Department of Agroindustrial Technology and also Department of Computer Science, Bogor Agricultural University (IPB). His research interests are in computational intelligence, parallel/super computing technology and their application to agroindustry. 
Roedhy Poerwanto (roedhy8@yahoo.co.id) is a Professor of Horticulture at Department of Agronomy and Horticulture, Bogor Agricultural University (IPB), Bogor, Indonesia. He has over 25 years of teaching and research experience in the fields of Horticulture, Plant Production Management, Advance of Plant Physiology, and Advance of Plant Production. He has authored of several papers published at national and international jurnals, such as Hort. J.; Jap. Soc. Hort. Sci, and Acta Hort. He earned his B.Sc. Honor in Agronomy from IPB, a MSc in Horticulture from Kagawa University, Japan, and Ph.D in Bioresource Production Sciences from Ehime University, Japan. He is Council member of International Society of Horticultural Sciences.

Miranda Meuwissen (Miranda.meuwissen@wur.nl) is an assistant professor of risk management in food supply chains at the Business Economics group of Wageningen University in the Netherlands. She has a PhD in agricultural risk management and an MSC in agricultural economics. Her research activities are mainly directed at the analysis of risk and risk mitigation strategies in food supply chains. 